\title{
Deformation mechanics of sputtered copper layers during nanoindentation tests
}

\author{
M. A. A. Afripin ${ }^{1}$, N. A. Fadil1 ${ }^{1}$ M. N. Tamin ${ }^{1, *}$ \\ 1 School of Mechanical Engineering, Faculty of Engineering, Universiti Teknologi Malaysia, 81310 Johor Bahru, Malaysia \\ Phone: +60127781410; Fax: +6075566159
}

\begin{abstract}
The mechanical properties of the thin sputtered copper layer on the $\mathrm{SiO}_{2}$-coated silicon substrate is needed as part of the requirements in quantifying the reliability of the ThroughSilicon Via (TSV) interconnects. In this respect, two different Cu coating layers, each from the different sputtering process, are examined. A series of nanoindentation tests are performed on the $\mathrm{Cu}$ coating layer samples with indenter speeds ranging from 80 to $400 \mathrm{~nm} / \mathrm{s}$, and the indentation depths of $320 \mathrm{~nm}$. The properties of elastic modulus, hardness and the hardening behavior of the $\mathrm{Cu}$ coating layers have been quantified. Results show that the coating with higher contamination of $C$ at 8.41 wt. \% displays a significant hardening and a peak load level, as reflected in the measured nanoindentation load-displacement curves. However, insignificant effect of the applied probe displacement speeds up to $400 \mathrm{~nm} / \mathrm{s}$ on the resulting properties of the coating is registered. The Johnson-Cook constitutive equation adequately describes the strain rate-dependent hardening behavior of the $\mathrm{Cu}$ coating layer.
\end{abstract}

ARTICLE HISTORY

Revised: $27^{\text {th }}$ Oct 2019

Accepted: $20^{\text {th }}$ Nov 2019

KEYWORDS

Hardness;

nanoindentation test; sputtered copper coating; Young's modulus.

\section{INTRODUCTION}

Thin copper layers are commonly deposited as copper $(\mathrm{Cu})$ traces on the printed wiring boards, and as a filler metal in Through-Silicon Vias (TSV)s. The conductive $\mathrm{Cu}$ traces and fillings function is to provide the current path for the microelectronic device. However, the temperature excursions during the reliability tests and operating conditions of the device induce stresses due to the mismatches of the coefficient of thermal expansions within the $\mathrm{Cu} /$ substrate bonded structure. Such a reliability concern over the failure of the copper layer has been addressed through experimental and computational studies e.g. [1,2]. Yielding and fracture of the copper layer has been identified as a cause of failure of the TSVs [3-6]. The failure processes of the TSV are dictated, to a large extent, by the deformation response of the conductive copper layer under the operating load conditions. Thus, the prediction of the device reliability and mechanical performance necessitates the deformation mechanics of the copper layer to be thoroughly understood and quantified.

Mechanical properties of $\mathrm{Cu}$ in the bulk material form are determined through tensile and fracture toughness tests on the samples of the metal. However, microtensile tests of freestanding $C u$ thin film specimen, and nanoscale cantilever beam tests for the $C u$ film have been performed to establish the properties of the material [6,7]. The Young's modulus, hardness and fracture toughness of $\mathrm{Cu}$ in the form of a coating layer is very different from the bulk properties. The yield stress of the $20 \mathrm{~nm}$-thick $\mathrm{Cu}$ film is ten times higher than its bulk counterpart [7]. The yield stress and elastic modulus are reported to be $765 \mathrm{MPa}$ and $129 \mathrm{GPa}$, respectively, while the typical corresponding properties of bulk copper are much lower at $70 \mathrm{MPa}$ and $117 \mathrm{Gpa}$, respectively. The observed difference in the mechanical properties is likely attributed to the different microstructures of the bulk and thin coating, as derived from the processing of the materials. Although the thin $C u$ coating layer produced by electroless plating and displayed similar grain size with that of sputtered coating layer, the latter exhibits diffused grain morphology [8].

Nanoindentation tests have also been performed on the coating layers to establish the load-displacement response, and extract the elastic modulus and hardness value of the materials [8-14]. During the test, the elastic-plastic response is measured during the loading of the hard indenter into the surface of the relatively softer coating layer. The peak load level is used to define the hardness value of the layer material. The Young's modulus is extracted from the initial unloading part of the load-displacement curve, assuming a purely elastic response. The influence of nanoindentation test variables, including the depth of the indent, the degree of the orthogonality of the indenter to the coating surface, and the coefficient of friction between the indenter and the coating material, on the extracted property values has been examined [15]. The true hardening behavior of the layer could be obtained using the loading portion of the measured load-displacement curve, through the inverse analysis approach [16-19]. When the sample shows the sign of a crack, the fracture toughness of the material could also be established [20].

This paper examines the deformation response of the sputtered $\mathrm{Cu}$ coating layer during the nanoindentation test. The effect of different probe speeds on the resulting hardness and modulus properties of the layer is examined. The strain ratedependent hardening behavior of the $\mathrm{Cu}$ coating layer is described. 


\section{MATERIAL AND EXPERIMENTAL PROCEDURES}

\section{Sputtered Copper Coating Layer}

Copper is sputtered onto the $\mathrm{SiO}_{2}$-coated silicon $(\mathrm{Si})$ substrate. The $\mathrm{Si}$ wafer with the orientation of [1 00 l has a thickness of $525 \mu \mathrm{m}$, while the $\mathrm{SiO}_{2}$ coating is $300 \mathrm{~nm}$-thick. The wafer is diced into square-shaped substrates measured $10 \times 10 \mathrm{~mm}^{2}$ for the sputtering process. Two different sets of $\mathrm{Cu}$-sputtered specimens are produced by different magnetron sputtering machines and processing parameters. The first set, labeled SP1 are sputter-coated using the Model TF450 PVD system. The other set of specimens, labeled SP2 are sputtered using the Evatec Clusterline CLC200 Metal Sputter. The substrate is maintained at room temperature during the sputtering process. The process parameters used are listed in Table 1.

Table 1. Process parameter settings for the sputtering of $C u$ on the substrates.

\begin{tabular}{lcc}
\hline Equipment/ & $S P 1$ & $S P 2$ \\
Process Parameters & TF450 Sputtering System, & Evatec Clusterline \\
\hline Sputtering Machine & SG Control Engineering & CLC200 Metal Sputter \\
Deposition Time $(S)$ & 3600 & 240 \\
Base Vacuum Pressure (Mbar) & $3.5 \times 10^{-5}$ & $1.25 \times 10^{-3}$ \\
Argon Flow Rate $\left(\mathrm{Cm}^{3} / \mathrm{Min}\right)$ & 15 & 24 \\
Dc Voltage $(\mathrm{V})$ & 430 & 720 \\
Dc Power $(\mathrm{Kw})$ & 0.103 & 12 \\
Dc Current $(A)$ & 0.24 & 16.7 \\
\hline
\end{tabular}

The thickness of the sputtered $C u$ coating samples is $8 \mu \mathrm{m}$. The samples are etched in a mixture of $25 \mathrm{ml} \mathrm{HCl,} 5 \mathrm{~g}$ ferric chloride and $100 \mathrm{ml}$ distilled water to better reveal the microstructure. The resulting microstructures of the $\mathrm{Cu}$ coating layer for the $S P 1$ and $S P 2$ samples are shown in the micrographs Figure 1 and Figure 2, respectively. The microstructure of the sputtered copper sample $S P 1$ shows a square-like shapes with sides measuring ranging from 13 to $20 \mu \mathrm{m}$. In contrast, the SP2 microstructure displays a smoother surface with randomly distributed fine sputtered copper particles. The relatively longer deposition time will likely cause the grains to grow and even recrystallize [21].

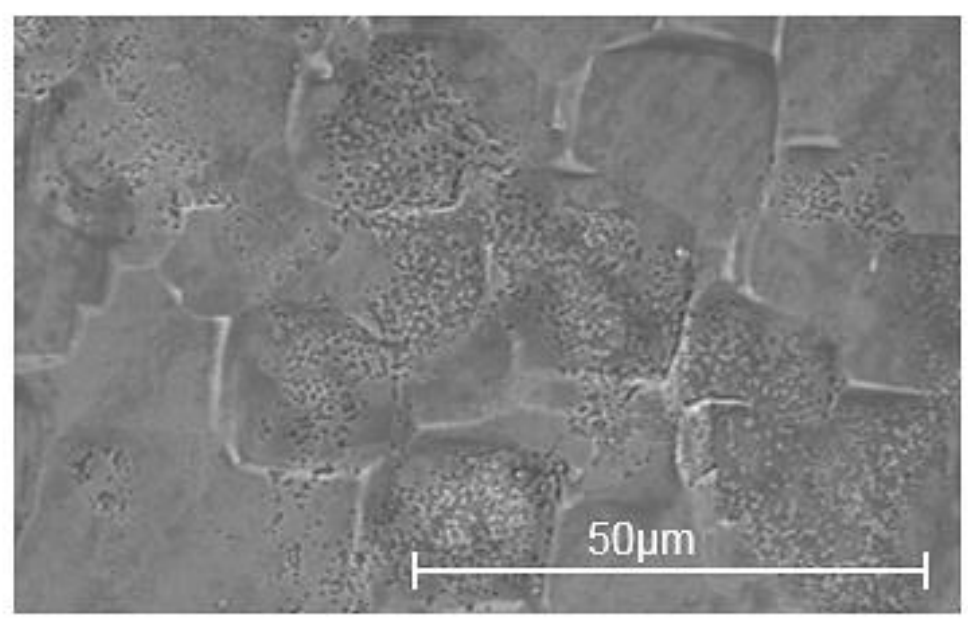

Figure 1. Surface structure of the $C u$ coating layer, $S P 1$. 


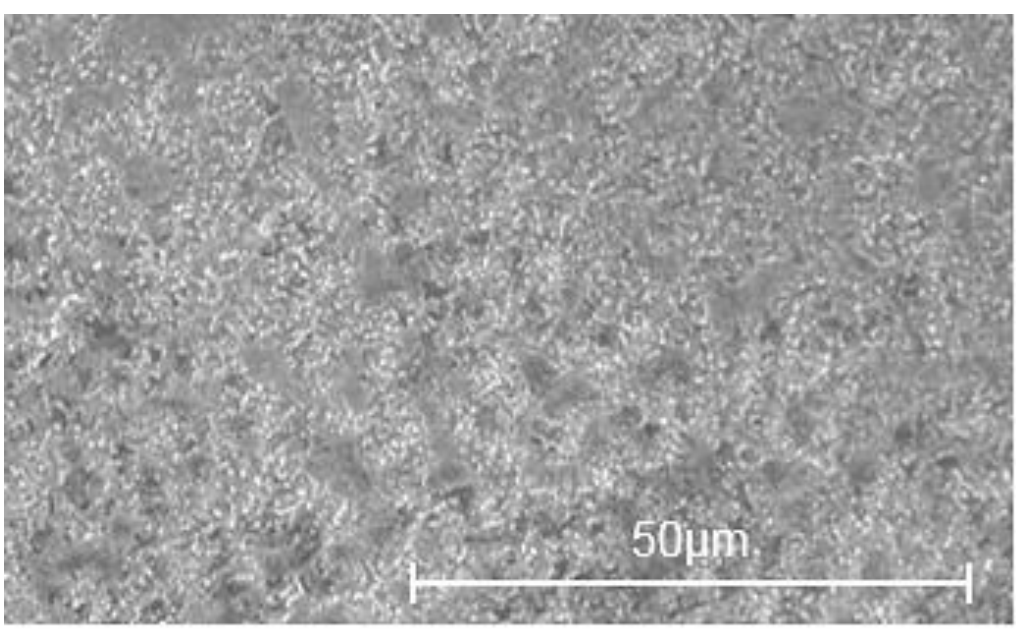

Figure 2. Surface structure of $\mathrm{Cu}$ coating layer, $S P 2$.

The corresponding composition analysis of the SP1 and SP2 sample, as represented by the EDX elemental spectrums, are compared in Figure 3(a) and (b), respectively. The primary constituents of the sputtered $\mathrm{Cu}$ coating layer are compared in Table 2. A higher carbon content of $8.41 \mathrm{wt}$. $\%$ is detected in the $C u$-coating for SP1 sample, possibly due to contamination induced from either $\mathrm{Cu}$-target poisoning or through the incorporation of the residual gas [22]. The excess carbon would likely result in higher strength of the $C u$ coating material. However, due to increase in carbon percentage, the brittleness of the material is also increased. The carbon will act as a barrier to dislocation mobility, where the movement is related to the ductility of materials. Metals with less carbon content are relatively ductile because the dislocations can easily glide on crystallographic planes during the deformation.

Table 2. Chemical composition (wt. \%) of the sputtered $C u$ coating layer.

\begin{tabular}{lcc}
\hline Element & $S P 1$ & $S P 2$ \\
\hline Carbon & 8.41 & 2.08 \\
Oxygen & 0.45 & 0.33 \\
Copper & 91.14 & 97.58 \\
\hline
\end{tabular}

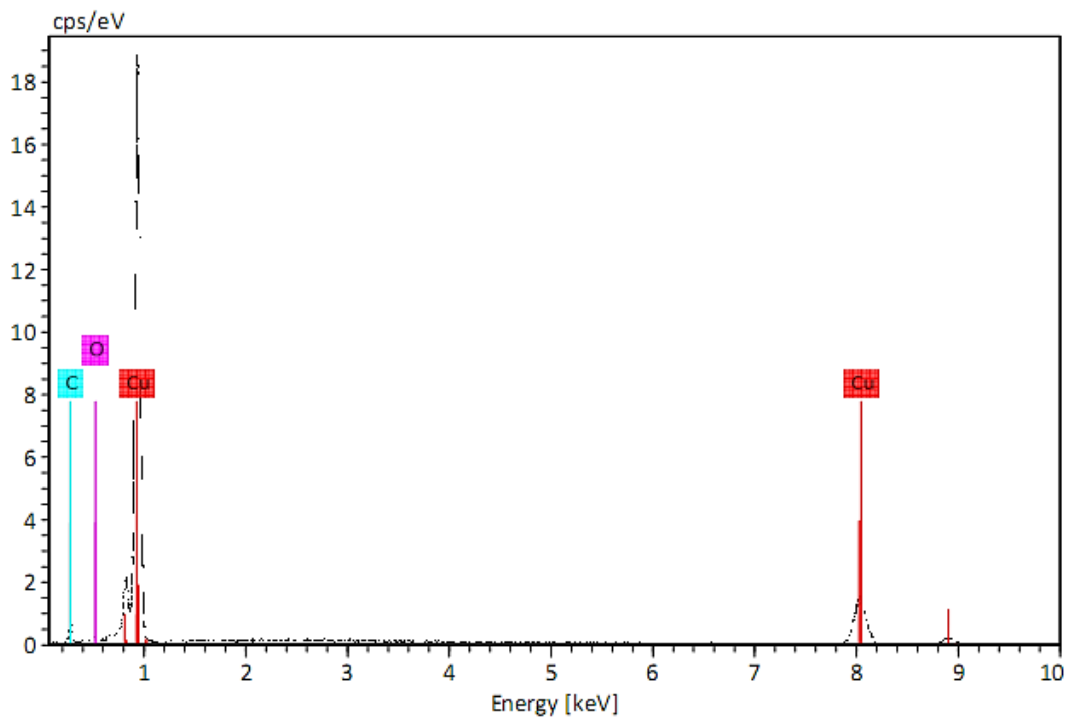

(a) 


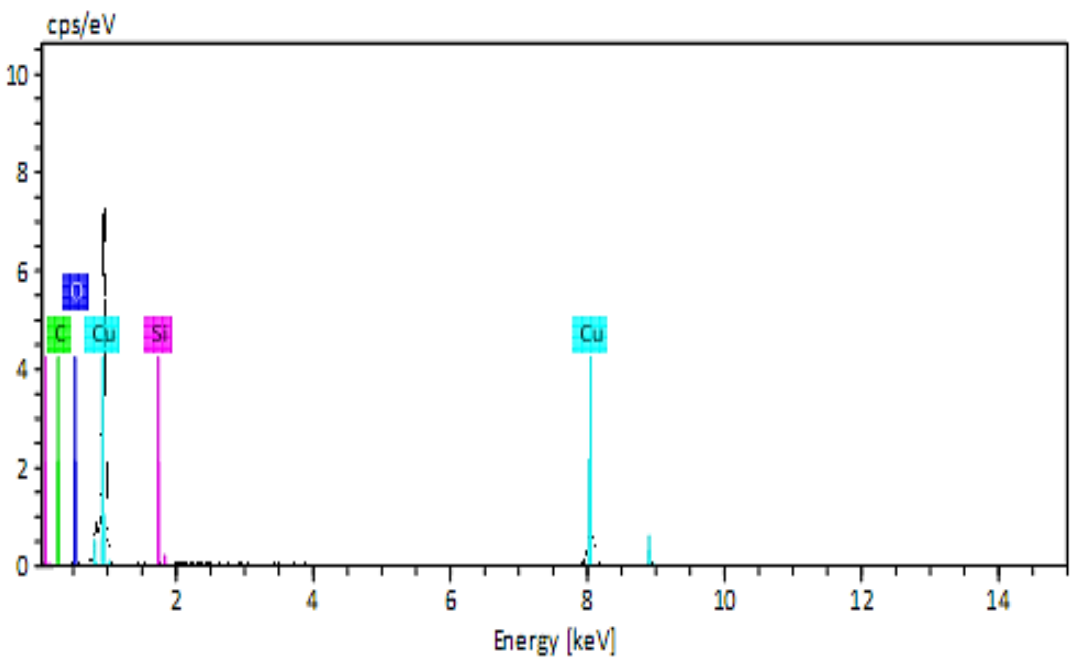

(b)

Figure 3. EDX elemental spectrum of the $C u$ coating layer of (a) sample $S P 1$ and (b) sample $S P 2$.

The resulting surface morphology of the $C u$ coatings is compared in Figure 4 (a) and (b) for the sample $S P 1$ and $S P 2$, respectively. These micrographs are obtained using the scanning probe microscope. Based on the sampling area of $10 x 10$ $\mu \mathrm{m}^{2}$, sample $S P 1$ exhibits a relatively flat surface with a low number of peaks and valleys. Although the highest peak, at $135 \mathrm{~nm}$ is found on sample $S P 1$, a larger number of peaks at $93 \mathrm{~nm}$ describe the morphology of sample $S P 2$, as shown in Figure 4 (b). The three deep valleys, as indicated in each micrograph, are the permanent indentation marks left by the nanoindentation tests to the specified depth of $320 \mathrm{~nm}$, and at the probe speed of $80 \mathrm{~nm} / \mathrm{s}$. The measured peaks and valleys, however, are much less than the magnitude of the indentation depth $(320 \mathrm{~nm})$. The morphology of the sputtered $\mathrm{Cu}$ coating surface could significantly affect the measured properties through non-orthogonality of the axis of the indenter with the local surface during the test, as discussed in the next section.

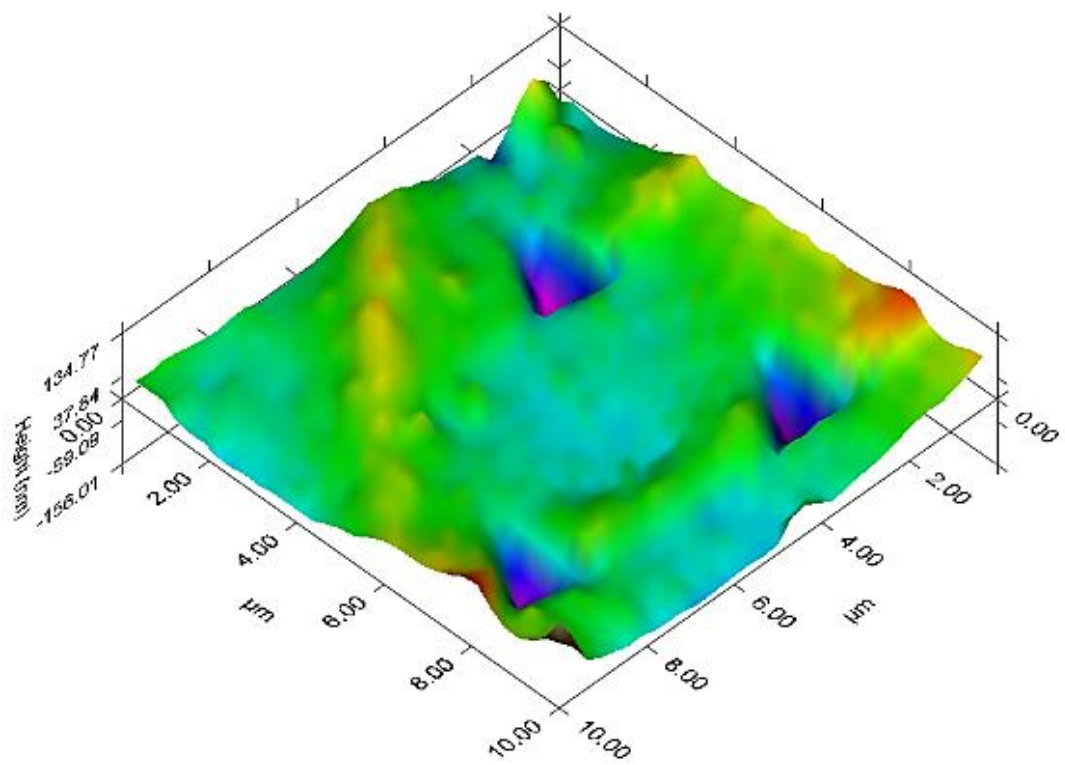

(a) 


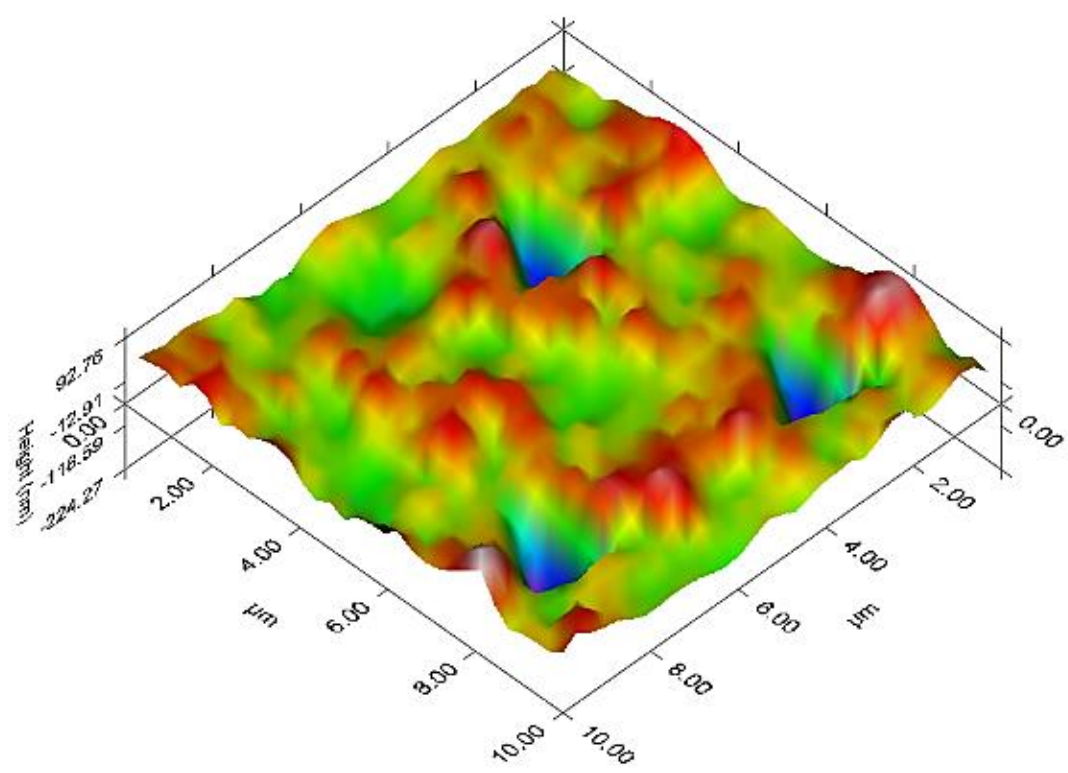

(b)

Figure 4. Scanning Probe Microscopy of the surface morphology of the (a) SP1 and (b) SP2 copper layer with Berkovich indentation marks $(h=320 \mathrm{~nm}, 80 \mathrm{~nm} / \mathrm{s})$.

\section{Nanoindentation Test}

Nanoindentation tests were performed on the sputtered copper coating samples using the Hysitron TI 750 Ubi Triboindenter. The indenter used is a Berkovich diamond indenter tip with a radius of $100 \mathrm{~nm}$. The inclination of the three surfaces of the pyramid-shaped indenter to the horizontal plane would produce an indentation mark of an equilateral triangle. The load and probe displacement resolution of the system is $1 \mathrm{nN}$ and $0.04 \mathrm{~nm}$, respectively. The tests conformed to the ASTM E2546-07 standard [8]. A valid nanoindentation test requires the penetration depth not to exceed $10 \%$ of the thickness of the coating layer.

The tests on samples $S P 1$ were initially conducted at $80 \mathrm{~nm} / \mathrm{s}$ to determine the valid minimum indentation depth [23]. The indentation depths range from 80 to $320 \mathrm{~nm}$ and limited by the upper range of the load cell at $12 \mathrm{mN}$. Then, samples $S P 2$ were tested at different specified probe speeds from 80 to $400 \mathrm{~nm} / \mathrm{s}$. The indenter is held for a period of 2 seconds at the maximum load followed by unloading, during each test. A minimum of three nanoindentation tests were repeated for each probe speed to establish the repeatability of the load-displacement (depth) response. The load-displacement data are recorded during the loading-unloading part of the nanoindentation cycle.

During the indentation process, the Berkovich indenter tip is driven into the surface of the $\mathrm{Cu}$ coating layer to the maximum specified depth, followed by unloading. A typical load-displacement curve is shown in Figure 5. The nonlinear loading part of the curve consists of the elastic-plastic deformation in forming the indent on the $\mathrm{Cu}$ coating surface, while the initial unloading part from the peak load level is assumed to be purely elastic. The residual displacement at zero load following the unloading process reflects the extent of the plastic deformation. The area enclosed by the curve represents the energy dissipated during the nanoindentation process.

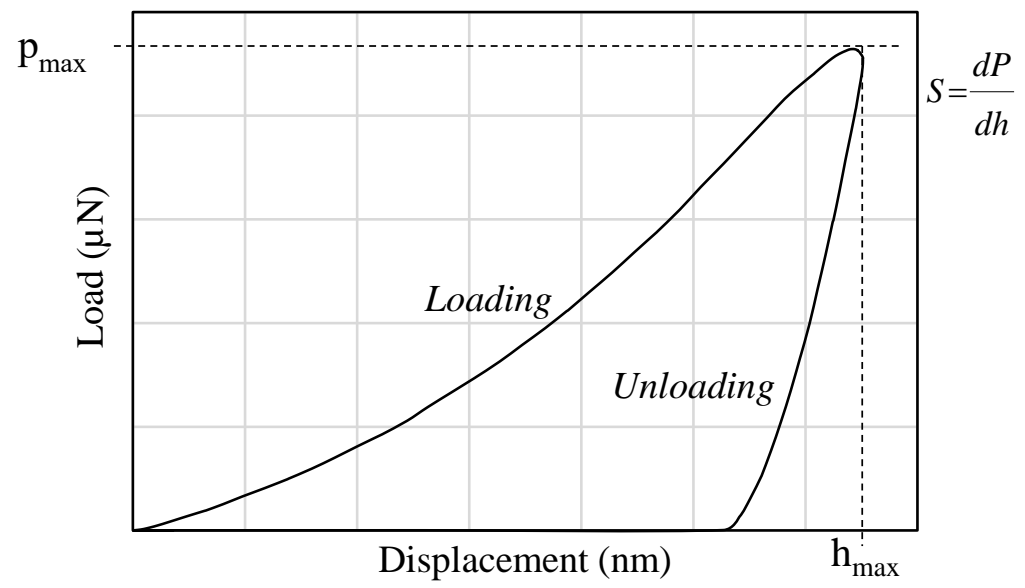

Figure 5. Typical load-depth curve of nanoindentation test. 
The mechanics of materials-based equations have been established to extract the hardness and elastic modulus of the material. The derivation of these equations is summarized here for convenience. The hardness measure, $H$ that quantifies the resistance of the material to plastic deformation is defined as [24]:

$$
H=P_{\text {max }} / A_{p}
$$

where $P_{\max }$ is the measured peak load and $A_{p}$ is the projected area between the Berkovich indenter and the $C u$ layer, defined as [25]:

$$
A_{p}=24.5 h_{c}^{2}
$$

In Equation. (2), the contact depth, $h_{c}=h_{\max }$ corresponds to the peak load, $P_{\max }$. The effect of the indenter shape on the calculated property values is represented by the coefficient of 24.5 for the Berkovich type indenter in Equation. (2). The radius of the indenter tip need to be considered to ensure the correct determination of the projected contact area at the nanoscale [26].

The Young's modulus of the copper layer, $E_{c}$ is determined as:

$$
E_{c}=\frac{1-v_{c}^{2}}{\frac{1}{E_{r}}-\frac{1-v_{i}^{2}}{E_{i}}}
$$

where $v_{I}=0.07$ and $v_{c}=0.30$ is the Poisson ratio of the diamond indenter, and $C u$ coating layer, respectively. The Young's modulus of the diamond indenter, $E_{i}=1140 \mathrm{GPa}$. The reduced modulus, $E_{r}$ is determined as:

$$
E_{r}=\frac{\sqrt{\pi}}{2} \frac{\beta S}{\sqrt{A_{p}}}
$$

where $S=d P / d h$ is the initial slope of the unloading line at the peak load. The Berkovich constant $\beta=1.034$.

\section{RESULTS AND DISCUSSION}

The deformation response of the $\mathrm{Cu}$ coating layer on the $\mathrm{SiO}_{2}$-coated $\mathrm{Si}$ substrate is presented and discussed in terms of the load-displacement curve from the nanoindentation test, the resulting elastic modulus and hardness measure, and the hardening curves of the coating layer.

\section{Load-Displacement Response}

The deformation responses of the sputtered $C u$ coating layer during the nanoindentation test at the probe speed of the $80 \mathrm{~nm} / \mathrm{s}$ and to the indentation depth of $320 \mathrm{~nm}$ are compared in Figure 6. The loading stage to the peak load is nonlinear with increasing slope of the load-displacement curve, indicating the hardening of the $C u$ layer due to the localized plastic deformation. The more gradual change in the slope of the loading curve for the coating layer sample SP2 suggests a lower hardening rate, while the lower peak load achieved reflects a relatively softer material than the coating sample SP1. The observed "blunt" peak of the curves at the loading-unloading transition could possibly be due to the inherent strain ratedependent deformation process, particularly in the vicinity of the indenter tip region. However, the initial unloading response for both samples is linear, reflecting an elastic behavior. The displacement at zero-load denotes the residual depth of the indent. The relatively softer $C u$ coating layer (SP2) experienced a deeper residual indent than that of the sample $S P 1$. The larger magnitude of the total dissipated energy during the nanoindentation process is associated with the sample $S P 1$, as shown by the greater area bounded by the load-displacement curve, than that for the sample $S P 2$. The observed difference in the mechanical responses is closely related to the different microstructure of the sputtered $C u$ coating layers. 


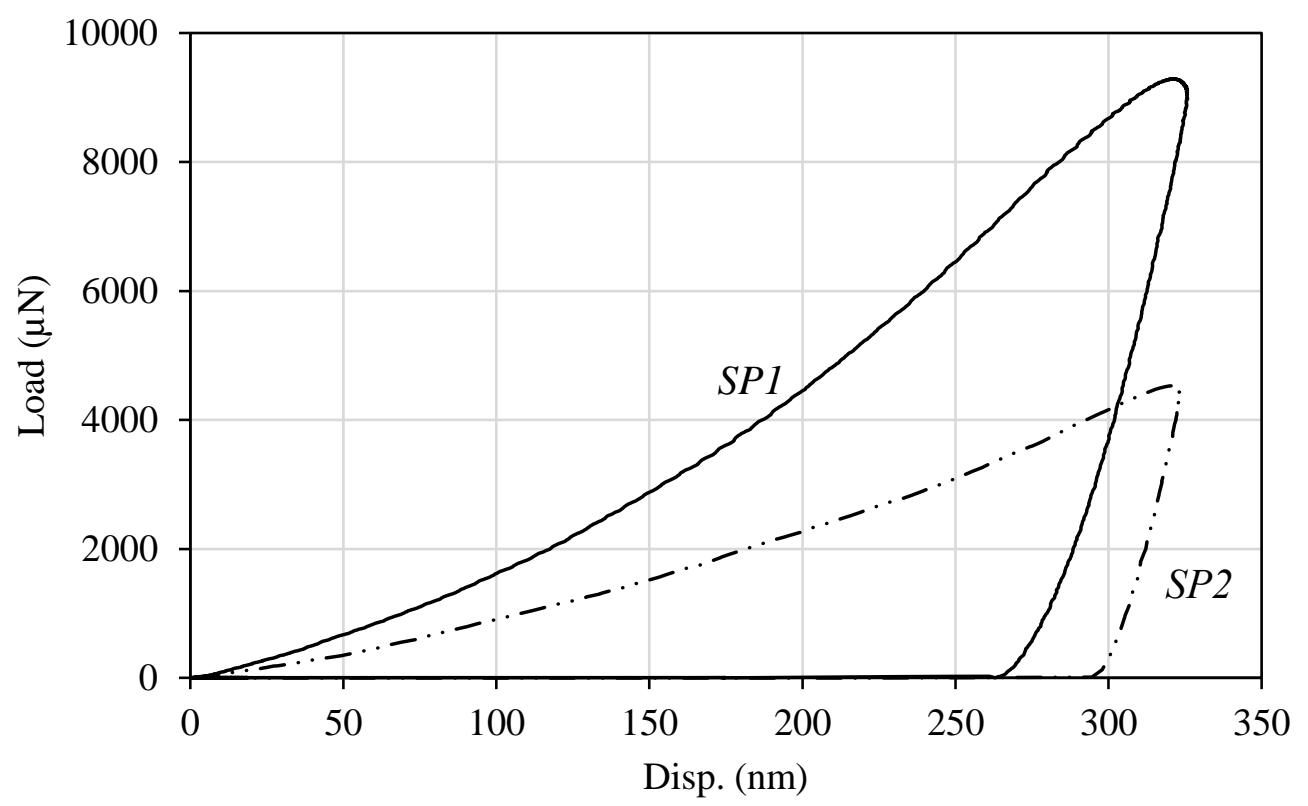

Figure 6. Load-displacement responses of the $C u$ coating samples during the nanoindentation test to the depth of 320 $\mathrm{nm}$, at $80 \mathrm{~nm} / \mathrm{s}$.

\section{Hardness Measure and Elastic Modulus}

A previous experimental study by the authors has indicated that a minimum indentation depth corresponding to $3 \%$ of the thickness of the coating is required to eliminate the effect of surface morphology on the measured properties of the coating layer [23]. The extracted properties of hardness and Young's modulus of the $C u$ coating layer, at different applied probe displacement rates, are shown in Figure 7 and 8, respectively. Each symbol represents three repeats of the measurements. Repeatability of the extracted data is excellent, as indicated by the small uncertainty range of the data.

The hardness of the sample $S P 1$ with an average value of $3.0 \mathrm{GPa}$ is higher than that of sample $S P 2$ at $1.3 \mathrm{GPa}$. This is likely due to the relatively higher contaminated $C$ content in the sample, as deliberated earlier (see Table 2). The insignificant effect of the higher applied probe displacement rates of up to $400 \mathrm{~nm} / \mathrm{s}$ on the hardness measure is observed. The Young's modulus of the sample $S P 1$ at an average value of $95 \mathrm{GPa}$ is only slightly lower than that of the sample $S P 2$ at $107 \mathrm{GPa}$. These measured values are comparable to the reported Young's moduli of thin $\mathrm{Cu}$ layers that range from 125 to $170 \mathrm{GPa}$, and significantly higher than that of the bulk copper at $70 \mathrm{GPa}[27,28]$. In addition, the modulus property values are independent of the probe displacement rates.

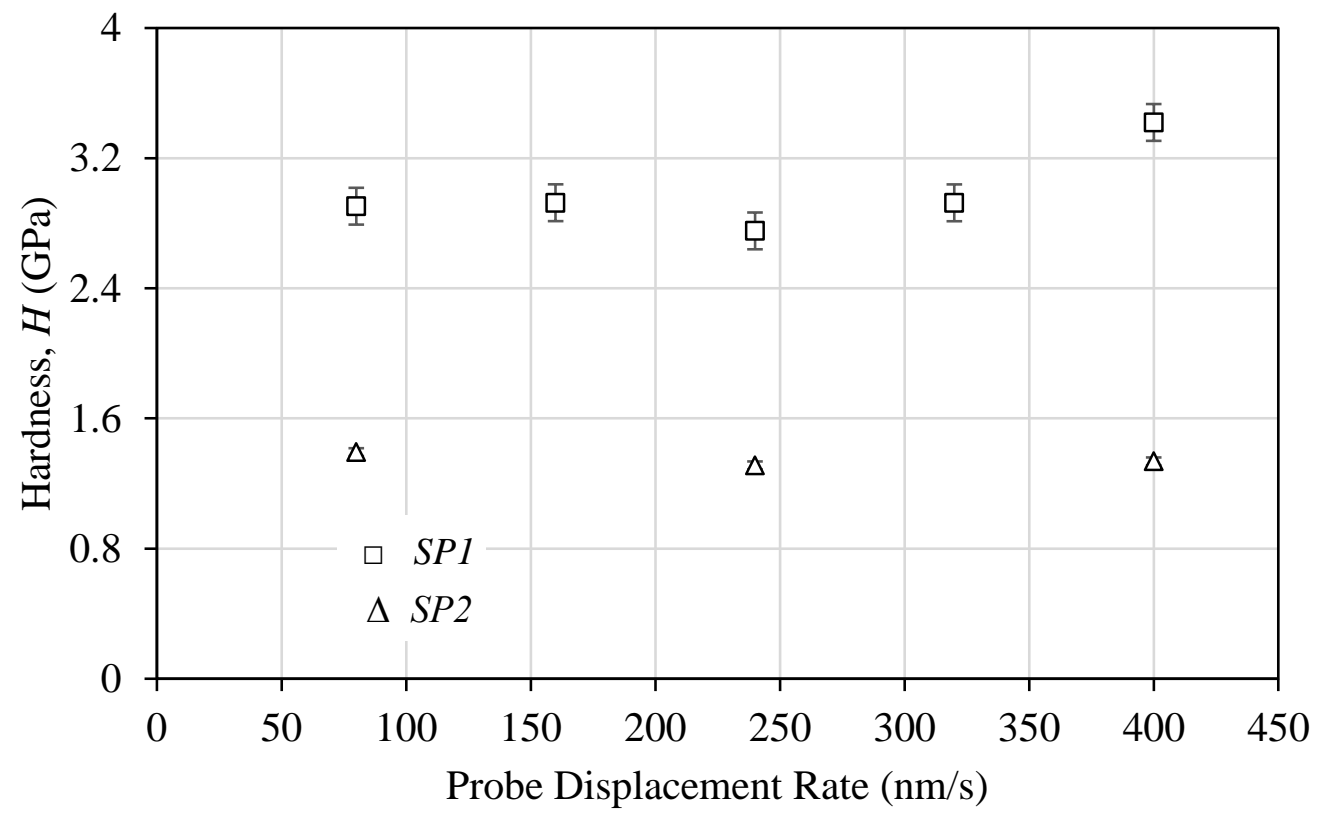

Figure 7. Hardness measure of the $C u$ coating samples at different applied probe displacement rates, $h=320 \mathrm{~nm}$. 


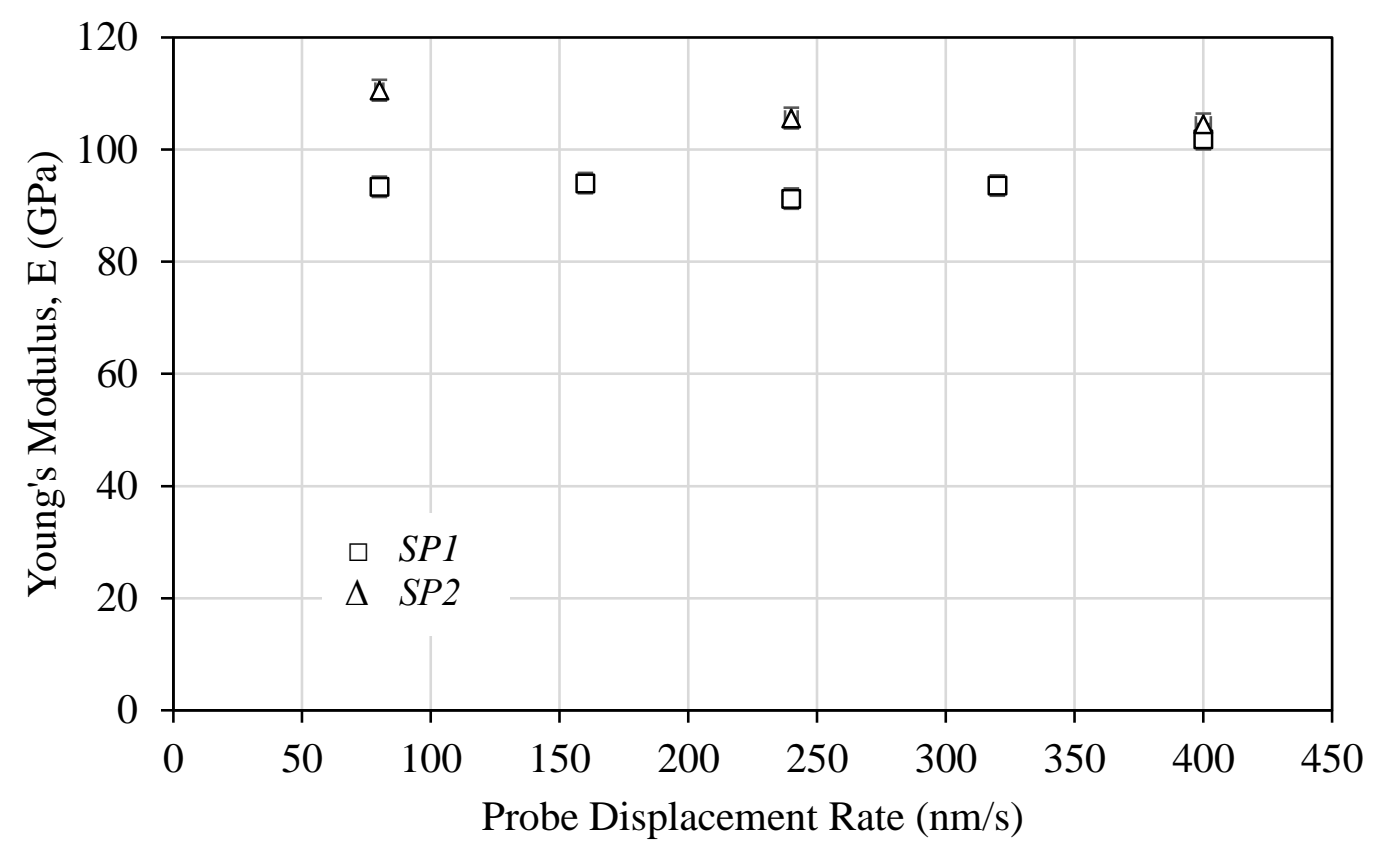

Figure 8. Young's modulus of the $C u$ coating samples at different applied probe.

\section{Stress-Strain Response}

The load-displacement curve for the loading stage of the nanoindentation test contains information on the hardening behavior of the $\mathrm{Cu}$ coating layer. However, the deformation is described by the 3-D stress and strain state. Nevertheless, the uniaxial true stress-plastic strain curve of the material could be extracted through the inverse analysis method. Details of the inverse analysis approach that employed the measured load-displacement curve from the nanoindentation test and the finite element simulation of the nanoindentation process is discussed elsewhere [19]. The resulting stress-plastic strain curves for the $\mathrm{Cu}$ coating layer, based on the sample $S P 2$, for two different strain rates are compared in Figure 9. The quasi-static initial yield strength of the $C u$ coating layer is $279 \mathrm{MPa}$. The higher strain rate of $0.608 / \mathrm{s}$ results in higher level of the initial yield strength of $520 \mathrm{MPa}$. In addition, the strain rate-dependent hardening behavior of the sputtered $\mathrm{Cu}$ coating layer could be represented by the Johnson-Cook constitutive equation as [19, 29]:

$$
\sigma=\left[279+(2633) \varepsilon^{(0.66)}\right]\left[1+(0.275) \ln \varepsilon^{*}\right]
$$

The first term on the RHS of Equation. (5) represents the hardening behavior while the second term represents the strain rate effects.

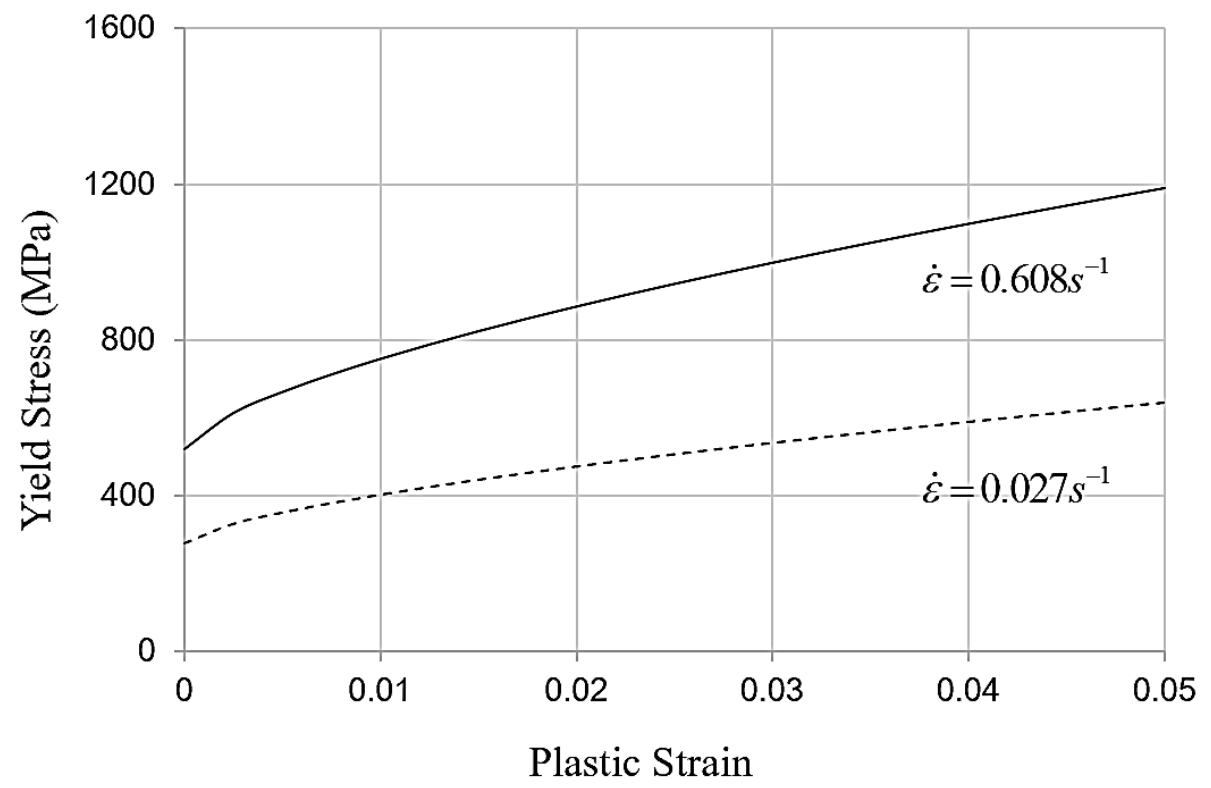

Figure 9. True stress-plastic strain curves of the sputtered $C u$ coating layer. 


\section{CONCLUSIONS}

The deformation response of the sputtered $\mathrm{Cu}$ coating on $\mathrm{SiO}_{2}$-coated $\mathrm{Si}$ substrate during the nanoindentation test has been established. The resulting properties of hardness, Young's modulus and hardening behavior have been quantified for two different microstructures of the coatings. Results show that:

(1) The $C u$ coating with higher contaminated $C$ content of $8.41 \mathrm{wt}$. \% displays a significant hardening and a peak load level, as reflected in the measured nanoindentation load-displacement curves.

(2) The insignificant effect of the applied probe displacement speeds up to $400 \mathrm{~nm} / \mathrm{s}$ on the resulting properties of the coating is registered.

(3) The hardening behavior of the $\mathrm{Cu}$ coating layer is adequately described by a strain rate-dependent stress-plastic strain curves through the Johnson-Cook constitutive equation.

\section{ACKNOWLEDGMENT}

This work is funded by the Collaborative Research in Engineering, Science and Technology (CREST) Malaysia and Universiti Teknologi Malaysia under the Grant No. P18C1-13 (UTM Project No. 4B118).

\section{REFERENCES}

[1] Chen S, Qin F, Zhao J, An T. TSV-Cu protrusion induced by thermal cycling test. In: $17^{\text {th }}$ International Conference on Electronic Packaging Technology (ICEPT); 16-19 August 2016.

[2] Ma HC, Guo JD, Chen JQ, Zhu QS, Shang JK. The reliability of through silicon via under thermal cycling. In: $16^{\text {th }}$ International Conference on Electronic Packaging Technology (ICEPT); 11-14 August, 2015.

[3] Jung M, Mitra J, Pan DZ, Lim SK. TSV stress-aware full-chip mechanical reliability analysis and optimization for 3D IC. Communicaton ACM. 2014;57(1):107-15.

[4] Jung M, Pan DZ, Lim SK. Chip/package mechanical stress impact on 3-D IC reliability and mobility variations. IEEE Transactions Computer-Aided Design of Integrated Circuits Systems. 2013;32(11):1694-707

[5] Demir K, Armutlulu A, Sundaram V, Raj PM, Tummala RR. Reliability of copper through-package vias in bare glass interposers. IEEE Transactions on Components, Packaging and Manufacturing Technology. 2017;7(6):829-37.

[6] Jung DH, Kim Y, Kim JJ, Kim H, Choi S, Song YH et al. Through-silicon via (TSV) defect modeling, measurement, and analysis. IEEE Transactions on Components, Packaging and Manufacturing Technology. 2017;7(1):138-52.

[7] Sumigawa T, Shishido T, Murakami T, Iwasaki T, Kitamura T. Evaluation on plastic deformation property of copper nanofilm by nano-scale cantilever specimen. Thin Solid Films. 2010;518(21):6040-7.

[8] ASTM E2546-15. Standard practice for instrumented indentation testing. ASTM International, West Conshohocken, PA. 2015.

[9] Fischer CAC. Nanoindentation. Mechanical Engineering Series: Springer; 2011.

[10] Beegan D, Chowdhury S, Laugier MT. A nanoindentation study of copper films on oxidised silicon substrates. Surface and Coatings Technology. 2003;176(1):124-30.

[11] Fang TH, Chang WJ. Nanomechanical properties of copper thin films on different substrates using the nanoindentation technique. Microelectronic Engineering. 2003;65(1-2):231-8.

[12] Amiri S, Xi C, Manes A, Giglio M, editors. An analysis of copper film mechanical properties by means of nanoindentation technique. Nanotechnology Materials and Devices Conference (NMDC). IEEE 9 $^{\text {th }}$, 12-15 October 2014.

[13] Fong W, Koay K, Azid I. Experimental evaluation on the silicon mechanical performance of electronic packaging. Journal of Mechanical Engineering And Sciences. 2017;11(1):2456-68.

[14] Jindal P, Jyoti J, Kumar N. Mechanical characterisation of ABS/MWCNT composites under static and dynamic loading conditions. Journal of Mechanical Engineering and Sciences. 2016;10(3):2288-99.

[15] Koloor SSR, Karimzadeh A, Tamin MN, Hamdi ASM. Effects of sample and indenter configurations of nanoindentation experiment on the mechanical behavior and properties of ductile materials. Metals. 2018;8(6):421.

[16] Giannakopoulos AE, Suresh S. Determination of elastoplastic properties by instrumented sharp indentation. Scripta Materialia. 1999;40(10):1191-8.

[17] Suresh S, Giannakopoulos AE. A new method for estimating residual stresses by instrumented sharp indentation. Acta Materialia. 1998;46(16):5755-67.

[18] Bucaille JL, Stauss S, Felder E, Michler J. Determination of plastic properties of metals by instrumented indentation using different sharp indenters. Acta Materialia. 2003;51(6):1663-78.

[19] Afripin MAA, Yoon CK, Tamin MN. An inverse approach for strain rate-dependent constitutive responses of copper layers. South East Asia, SIMULIA Regional Users Conference. Singapore 2016.

[20] Ayatollahi MR, Karimzadeh A. Determination of fracture toughness of bone cement by nano-indentation test. International Journal of Fracture. 2012.

[21] Bergshoeff. Microstructure analysis of PVD deposited thin copper films. 2011.

[22] Boo JH, Jung MJ, Park HK, Nam KH, Han JG. High-rate deposition of copper thin films using newly designed high-power magnetron sputtering source. Surface and Coatings Technology. 2004;188-189:721-7. 
[23] Afripin MAA, Fadil NA, Hamid MFA, Yoon CK, Cheah BE, Razak BBA et al. Rate-dependent responses of electroless plated and sputtered copper layer during nanoindentation loading. 2016 IEEE $37^{\text {th }}$ International Electronics Manufacturing Technology (IEMT) \& 18 ${ }^{\text {th }}$ Electronics Materials and Packaging (EMAP) Conference; 2016 20-22 Sept. 2016.

[24] Oliver WC, Pharr GM. Measurement of hardness and elastic modulus by instrumented indentation: Advances in understanding and refinements to methodology. Journal of materials research. 2004;19(01):3-20.

[25] Oliver WC, Pharr GM. An improved technique for determining hardness and elastic modulus using load and displacement sensing indentation experiments. Journal of Materials Research. 1992;7(06):1564-83.

[26] Hay JL, GM P. ASM handbook mechanical testing and evaluation. Kuhn H MD, editor: ASM International. 2000:232-43.

[27] Wu W, Qin F, An T, Chen P. Experimental and numerical investigation of mechanical properties of electroplating copper filled in through silicon vias. IEEE Transactions on Components, Packaging and Manufacturing Technology. 2016;6(1):23-30.

[28] Okoro C, Levine LE, Ruqing X, Obeng YS, editors. Experimentally, how does Cu TSV diameter influence its stress state? Electronic Components and Technology Conference (ECTC), IEEE 65 ${ }^{\text {th }}, 26-29$ May 2015.

[29] Johnson GR, Cook WH, editors. A constitutive model and data for metals subjected to large strains, high strain rates and high Temperatures. Proceedings of the $7^{\text {th }}$ International Symposium on Ballistics; 1983. 